a primary operation was performed in 1868, the diagnosis being verified by microscopic examination of the tumour after its removal, and where secondary grow ths have occurred in the cicatrix in 1887-i.e., after an immunity of nineteen jears. I wish Mr. Pemberton would define the sense in which he employs the term "cure," and state whether he considers in the case now cited that Dr. Smith "cured" his patient of "cancer" in 1868. Will Mr. Pemberton also inform me in what sense "cancer infiltrating the textures immediately around its origin" differs from cancer as defined by myself in your issue of the $3 \mathrm{rd}$ inst.; ${ }^{2}$ and how he recognises clinically the commencement of the process of "contamination of the adjacent glands"?

From the evidence before us I cannot at present regard certain cases treated after Mr. Clay's method other than instances in which cancer has been cured, and his success has led me to try Chian turpentine numerous times at the Cancer Hospital. Though unable to point to a single instance in which cancer has been yet cured in my own practice by the internal administration of Chian turpentine, either alone or in combination with local applications-and the value of the latter must not be underrated,--my experience has caused me to regard the remedy as valuable. It checks discharge and hæmorrhage, and allays pain. It would also be most unfair were I to neglect to state that the cases in which I have administered chian turpentine--and beneficially - were all unsuited for operation on account of the extent of the disease. Had the drug therefore been exhibited at an earlier date, the natural course of the disease might have been arrested. I have employed the drug in a case of perineal fistula, where it acted similarly to copaiba and cubebs.

This observation suggests the possibility that if Chian turpentine will operate favourably upon cancer, its allies may be found possessed of similar or more potent properties. Let me add that, for my part, I am determined to continue an unprejudiced trial of Chian turpentine, and to publish the results at a later period. In the meantime, I should be happy to assist others, having the same object in view, in making careful diagnoses of cases in which cancer presumably exısts before the exhibition of the remedy.

I am, Sirs, yours faithfully,

Chas. E. Jennings.

Upper Brook-street, Grosvenor-square, W., Dec. 10th, 1887.

ANTIPYRIN IN THE SICKNESS OF PREGNANCY. To the Editors of THE LANCET.

SIRs, - I have recently had an opportunity of testing the value of antipyrin as a moderator of the reflex excitability of the nervous centres in a case of obstinate vomiting of pregnancy. Mrs. - - a lady now in the sixth month of her fourth pregnancy, has been suffering from this annoyance for the last ten woeks. All the usual remedies have been tried without any success, and the sickness when I advised antipyrin commenced every day as soon as the patient awoke, about 7 A.M., and continued at intervals until midday. The first morning the medicine was used it was immediately vomited, and the sickness continued as usual. I then advised that a dose (of fifteen grains) should be taken the last thing at night. The following morning the patient felt comfortable, and got up without being sick; but shortly afterwards the nausea was experienced, and although another dose of antipyrin was taken it did not remain upon the stomach, and for the rest of the morning there was the usual sickness. The dose was then doubled, and $I$ recommended that in the morning the medicine should be taken before any attempt was made to move out of bed. This controlled the sickness until 10 A.M., when it again recurred, and lasted a couple of hours. Not thinking it advisable to push the administration of antipyrin, under the special circumstances of the case, beyond two doses of thirty grains each, I advised the patient to remain content with this half-result.-I am, Sirs, yours sincerely,

Paris, Dec. 12th, 1887. Oscar Jennings.

\section{ETIOLOGY OF PNEUMONIA.}

To the Editors of THE LANCET.

SIRS,-In reference to an article on pneumonia dealing with the views of Dr. Baker (of the United States) on its causation, it may be mentioned that an investigation into the statistics of chest diseases in the British army would pro-

2 The Lancet, p. 1142 bably fully confirm his statements. The doctrine of chill from external cold had been generally accepted for practice, and on its authority the introduction of the wearing of flannel shirts by the soldiery was strongly recommended and carried into use. The result in the diminution of cases and mortality from chest complaints caused by exposure to weather was surprising, and has continued equally successful. There may be discovered other agencies, chemical and vital acting along with and influencing pneumonia, and developed by the vital disturbance that then takes place in the lungs but experience leads to the belief in the atmospheric agency of cold applied directly to the outside of the chest, and that it (presupposed to be an entity) then penetrates by conduction through the walls of the chamber to the pleuræ, and then into the lobules of the lungs lying next to them. All the vessels are at first contracted to their finest calibres, both on the skin and in the lungs, and so remain for hours probably, causing the feeling of chill. Next, on the patient's removal to house or hospital, with a warmer air, reaction sets in, the circulation rushes into the emptied vessels, already weakened, distends them, and produces the stagnation and effusion called inflammation.

I am, Sirs, yours truly,

J. W. BLACK, Surgeon-Majcr.

Royal L nited Service Institution, Whitehall, London.

\section{POOR-LAW MEDICAL OFFICERS' ASSOCIATION。} To the Editors of THE LANCET.

SIRs,--Will you kindly insert the enclosed resolution, passed at our Council meeting on December 8th?

"Several cases having been brought before the Council in which alleged errors of diagnosis had been publicly reported, and consequently affecting the professional characters of district medical officers and others, the Council trust that more consideration will be shown by medical officers of health and medical superintendents of public institutions in the expression of any adverse opinions."

I am, Sirs, yours truly,

Dec. 14th, 1887.

$$
\text { J. WICKHAM BARNES. }
$$

\section{NORTHERN COUNTIES NOTES.}

(From our own Correspondent.)

THE HEALTH OF NEWCASTLE.

THe high rate of mortality prevalent for some time in the city of Newcastle-on-Tyne has been a foremost subject of conversation here amongst all classes. The daily press also has freely ventilated the matter, and indeed the whole machinery of inquiry has been set a-going down to "interviewing," and all sorts and conditions of practitioners have been pressed to give "their views." In the fow remarks bere set forth I may say I have not been "interviewed," that my experience of Newcastle extends over twentyseven years of practice, and that I have freely conversed with men in the profession and others who take an interest in sanitary matters. The principal factors in producing the late high figures in the deatb-rate are: the geographical position of Newcastle, standing as it does in the narrowest part of England; the late meteorological conditions, mostly characterised by change - not, indeed, intense cold, but cold, with damp, hoar frosts, succeeded by a rising thermometer and westerly or southwesterly wind, veering often to the north and north-east; and, again, fogs-frosts not usually so common here at this season. Add these conditions to a clay soil, on which this city is built, and we have some of the strongest causes for general ill-health in the community. Unlike other cities, the best or more fashionable quarters are not in the west but in the north and east end. The west end of the city is built on a good slope, and in most parts on high ground, and has rather a better foundation as regards the character of the clay. In some of the north districts the clay extends down fully nine feet, so that in damp weather there must be a greater retention of moisture. The School Board regulations have been blamed for much of the illness. I do not agree with this, for it will always be to the interest of the School Board and its officers to keep up a good standard of health, as securing a good general attendance but boards are not very sensitive bodies, and I may leave the 